\title{
Novel spotted fever group rickettsiae in Haemaphysalis qinghaiensis ticks from Gansu, Northwest China
}

\author{
Jifei Yang ${ }^{1}$, Zhancheng Tian', Zhijie Liu', Qingli Niu', Rong Han', Youquan Li', Guiquan Guan', Junlong Liu', \\ Guangyuan Liu', Jianxun Luo ${ }^{1 *}$ and Hong Yin ${ }^{1,2^{*}}$
}

\begin{abstract}
Background: Rickettsia spp. are obligate intracellular bacteria and well known as transmitted by arthropods. These pathogens have a broad geographic distribution and a high degree of biological and clinical diversity. This study was conducted to determine the prevalence and molecular characterization of Rickettsia spp. in ticks collected from Gansu, where Borrelia burgdorferi sensu lato and Anaplasma phagocytophilum were previously reported in ticks and ruminants.

Methods: A total of 1,583 questing Haemaphysalis qinghaiensis ticks were collected and tested for the presence of Rickettsia spp. gltA gene by PCR. Samples positive for gltA were examined by specific primers targeted for the ompA gene of SFG rickettsiae. The infections were further validated by sequencing and positive samples were genetically characterized based on the gltA and ompA genes.
\end{abstract}

Results: In total, Rickettsia spp. infection was found in 179 (18.5 \%) H. qinghaiensis tick pools by using PCR and primers specific for the gltA gene. Of those, 157 (16.3\%) tick pools were positive for SFG rickettsiae by PCR based on ompA gene. Amplification and molecular analysis of the nucleotide sequences of gltA and ompA genes indicated three potential novel spotted fever group rickettsiae in $\mathrm{H}$. qinghaiensis ticks. These three potential novel spotted fever group rickettsiae were clustered together in a subgroup, which represents a sister taxon to and separates from other known four SFG rickettsiae subgroups.

Conclusions: This study revealed a high infection rate of SFG rickettsiae in H. qinghaiensis ticks in northwest China. Three potential novel spotted fever group rickettsiae classified into a novel SFG rickettsiae subgroup were identified and named "Candidatus Rickettsia gannanii" related strains in recognition of the location where it was first detected.

Keywords: gltA gene, ompA gene, Tick, Rickettsia sp, SFG rickettsia

\section{Background}

Rickettsiae are highly specialized obligate intracellular gram-negative microorganisms that can cause disease in human and/or in other vertebrate and invertebrate hosts with diverse clinical presentations, from asymptomatic to severe [1]. Recently, rickettsioses have been viewed as emerging or reemerging diseases with an almost worldwide distribution $[2,3]$. Rickettsia was shown to be a

\footnotetext{
*Correspondence: luojianxun@caas.cn; yinhong@caas.cn

'State Key Laboratory of Veterinary Etiological Biology, Key Laboratory of Veterinary Parasitology of Gansu Province, Lanzhou Veterinary Research Institute, Chinese Academy of Agricultural Science, Xujiaping 1, Lanzhou, Gansu 730046, P. R. China

Full list of author information is available at the end of the article
}

large genus encompassing at least 30 recognized species, 19 of which were considered to be human pathogens $[4,5]$. A number of other putative species of Rickettsia have also been reported on the basis of phylogenetic analyses of different gene loci [5-8]. Rickettsia spp. are usually associated with arthropods, and ticks, louse, mites and fleas had been recognized as competent vectors of rickettsial agents [9-12]. Recently, mosquitoes were considered as potential vectors for R. felis [13]. In addition, numerous Rickettsia spp. or specific DNA have been detected in arthropods other than the aforementioned vectors [2], such as booklice, true bugs, white fly, etc. 
Historically, most of the recently discovered pathogenic Rickettsia spp. were first identified in arthropods and much later were reported in human cases, such as $R$. parkeri and $R$. slovaca. The former was identified in Amblyomma maculatum in 1937, and it was not until 60 years later that the first human case of $R$. parkeri infection was described [14]; the latter was described in Dermacentor marginatus in 1968, but the first documented case was reported several years later [1]. Recently, with the development of molecular techniques, new Rickettsia spp. have been identified in places where no rickettsioses had been reported, and some of these have been recognized as human pathogens [15]. The novel identified rickettsial species have enriched our understanding of rickettsioses. The objective of this study was to identify the rickettsial species in ticks collected from a specific area of QingTibetan Plateau that had not been previously described for rickettsioses.

\section{Methods}

\section{Study site and tick collection}

The study site is located on the northeast edge of the Qing-Tibetan Plateau with an important forest zone and the main pasturing area in Gannan Tibetan Autonomous Prefecture $\left(33^{\circ} 06^{\prime \prime} \sim 36^{\circ} 10^{\prime \prime} \mathrm{N}, 100^{\circ} 46^{\prime \prime} \sim 104^{\circ} 44^{\prime \prime E}\right)$ that relies heavily on sheep, goat and yak farming for protein and local economy. Its average altitude is over $3,000 \mathrm{~m}$. The annual average temperature here is $3.1{ }^{\circ} \mathrm{C}$ and annual precipitation is $582.7 \mathrm{~mm}$. A total of 1,583 questing ticks were collected monthly between March and May 2011 by flagging the undergrowth with a flannel cloth. All ticks were identified as Haemaphysalis qinghaiensis based on the taxonomic key and morphological criteria [16].

\section{DNA extraction}

Tick larvae and nymphs were pooled before DNA extraction; each tick pool consisted of 10 larvae or 5 nymphs, or a single adult tick. DNA was extracted by using the Puregene DNA purification kit (Qiagen, Beijing, China) according to the protocols.

\section{$P C R$ reactions}

The extracted DNA was examined for the presence of Rickettsia spp. gltA gene by using RpCS.409d and RpCS.1258n primers (5'-CCTATGGCTATTATGCTT GC-3'; 5'-ATTGCAAAAAGTACAGTGAACA-3') and amplified a 770-bp fragments as described by Roux et al. [17]. Each positive sample was amplified with SFG rickettsiae specific primers $\operatorname{Rr} 190.70$ and $\operatorname{Rr} 190.701$ (5'-ATGGCGAATATTTCTCCAAAA-3'; 5'-GTTCCGT TAATGGCAGCATCT-3') based on ompA gene and amplified at 617-680-bp fragments [18]. The reaction was performed in an automatic thermocycler (Bio-Rad, Hercules, USA) with a total volume of $25 \mu \mathrm{L}$ containing $2.5 \mu \mathrm{L}$ of $10 \times$ PCR buffer $\left(\mathrm{Mg}^{2+}\right.$ Plus $), 2.0 \mu \mathrm{L}$ of each dNTP at $2.5 \mathrm{mM}, 1.25 \mathrm{U}$ of Taq DNA polymerase (TaKaRa, Dalian China), $2.0 \mu \mathrm{L}$ of template DNA, $1.0 \mu \mathrm{L}$ of each primer $(10 \mathrm{pmol})$, and $16.25 \mu \mathrm{L}$ of distilled water. Positive and negative controls were included in each run. Cycling conditions for glt $A$ and ompA amplification were: $4 \mathrm{~min}$ of denaturation at $94{ }^{\circ} \mathrm{C}, 35$ cycles at $94{ }^{\circ} \mathrm{C}$ for $30 \mathrm{~s}$, annealing for $30 \mathrm{~s}$ at $55^{\circ} \mathrm{C}$, and $72{ }^{\circ} \mathrm{C}$ for $45 \mathrm{~s}$, with a final extension step at $72{ }^{\circ} \mathrm{C}$ for $10 \mathrm{~min}$. PCR products were visualized by UV transillumination in a $1.0 \%$ agarose gel following electrophoresis and staining with ethidium bromide.

\section{Sequencing and phylogenetic analyses}

The PCR products of the partial gltA and ompA gene were purified using the TaKaRa Agarose Gel DNA purification Kit Ver.2.0 (TaKaRa, Dalian, China), ligated into pGEM-T Easy vector (Promega, USA), and transformed into Escherichia coli JM109 competent cells. Two recombinant clones were selected for sequencing using BigDye Terminator Mix (Sangon, Shanghai, China). The sequences obtained in this study were deposited in the GenBank (not including identical sequences) under accession nos. KT921891-KT921896. Sequences were analyzed by a BLASTn search in GenBank or by using the Clustal W method in the MegAlign software (DNAStar, Madison, WI). Phylogenetic trees were then based on the sequence distance method using the neighbor-joining (NJ) algorithm with the Kimura twoparameter model of the Mega 4.0 Software [19].

\section{Statistical analysis}

The infection rates of Rickettsia infection in $H$. qinghaiensis ticks of larval and nymphal stages were estimated using the minimum infection rate [MIR, (the number of positive pools/the total number of ticks tested) $\times 100 \%]$. The results were analyzed using a Chi-square test in Predictive for Analytics Software (PASW) Statistics 18. A difference was considered statistically significant at $P<0.05$.

\section{Ethical approval}

This study was approved by the Animal Ethics Committee of Lanzhou Veterinary Research Institute, Chinese Academy of Agricultural Sciences.

\section{Results}

The DNA of Rickettsia spp. was found in 179 (18.5 \%) $H$. qinghaiensis tick pools by using PCR and primers specific for the gltA gene (Table 1). The infection rate of Rickettsia spp. was $14.7 \%$ for adult $H$. qinghaiensis ticks. The MIRs were $5.9 \%$ and $10.2 \%$ for the larva and 
Table 1 Prevalence of Rickettsia spp. in Haemaphysalis qinghaiensis ticks

\begin{tabular}{lllllll}
\hline Tick life stage & No. of ticks & Pool sizes & No. of pools & $\begin{array}{l}\text { No. (\%) of tick pools } \\
\text { positive for gltA }\end{array}$ & $\begin{array}{l}\text { No. of tick pools positive for } \\
\text { ompA/no. examined/(\%) }\end{array}$ & $\begin{array}{l}\text { No. (\%) of tick pools positive for } \\
\text { gltA and negative for ompA }\end{array}$ \\
\hline Larva & 460 & 10 & 46 & $27 /(58.7)$ & $20 / 27 /(43.5)$ & $7 /(15.2)$ \\
Nymph & 295 & 5 & 59 & $30 /(50.8)$ & $29 / 30 /(49.2)$ & $1 /(1.7)$ \\
Female & 506 & 1 & 506 & $80 /(15.8)$ & $67 / 80 /(13.2)$ & $13 /(2.7)$ \\
Male & 322 & 1 & 322 & $42 /(13.0)$ & $41 / 42 /(12.7)$ & $1 /(0.3)$ \\
Total & 1583 & - & 966 & $179 /(18.5)$ & $157 / 179 /(16.3)$ & $22 /(2.3)$ \\
\hline
\end{tabular}

$\mathrm{N}=$ number of tested ticks; (\%) - prevalence of infection

${ }^{a}$ Only ticks positive for the gltA gene were tested for the SFGR ompA gene

nymphs, respectively. Out of all tick specimens that tested positive for Rickettsia, 157 (16.3\%) tick pools were positive by PCR for the primer set $\operatorname{Rr} 190.70$ and $\operatorname{Rr} 190.701$ for the SFG rickettsiae ompA gene. The infection rate of SFG rickettsiae was $13.0 \%$ for adult H. qinghaiensis ticks. The MIRs were $4.3 \%$ and $9.8 \%$ for the larva and nymphs, respectively. Twenty-two $(2.3 \%)$ tick pools that tested positive for the genus Rickettsia gltA gene were negative for SFG rickettsiae by using ompA primers. The infection rates of SFG rickettsiae were comparable in female and male ticks (13.2\% versus $12.7 \%, P>0.05)$.

Seventy-one sequences (36 for glt $A$ and 35 for ompA) were obtained in this study. Nucleotide sequence identities ranged from $97.0 \%$ to $98.4 \%$ for the $g l t A$ gene and from $87.8 \%$ to $96.7 \%$ for the ompA gene. After BLAST and CLUSTAL W alignment, 36 sequences of the gltA gene fragment $(770 \mathrm{bp}$ ) were classified into three sequence types (ST), representing three different Rickettsia spp. isolates. ST1-3 had the highest nucleotide sequence similarities $(99.0 \%, 97.7 \%$ and $97.4 \%)$ to $R$. raoultii (GenBank accession no. KT261764). PCR amplification and sequencing showed the target fragments of the ompA gene were 617, 680 and 641 base pair for Rickettsia ST1-3, respectively. The sequence similarity of the ompA gene sequences of ST1-3 with that of $R$. raoultii was $79.4 \%, 81.1 \%$ and $81.4 \%$, respectively, which did not meet the threshold for $R$. raoultii [20].

Phylogenetic analyses revealed that the gltA gene sequences obtained in this study formed three distinct and well-defined clades inside the SFG rickettsiae (Fig. 1). Cluster one (ST1: Y27-1, Y34-5, etc.) was closely related to and clustered within the same clade as Rickettsia sp. strain "Tick-201-Mie-Hfla" isolated from H. flava found in Japan and the Candidatus Rickettsia principis isolated from $H$. japonica in Russia (GenBank accession no. JQ697957 and AY578115) [21]. Cluster two (ST2: F23-1, F23-2, F218-2 and F218-3) and three (ST3: F203-3, F290-3, M17-2, M17-3, F107-2 and F326-2) clustered independently from all known SFG rickettsiae sequences available on GenBank (Fig. 1). All SFG rickettsiae strains identified in $H$. qinghaiensis ticks were clustered together in a subgroup, which represents a sister taxon to and separates from other known four SFG rickettsiae subgroups (Fig. 1). Similar phylogenetic organizations were inferred from the sequence analysis of ompA gene (Fig. 2).

\section{Discussion}

Rickettsia spp. have been recognized as emerging or reemerging pathogens of public health relevance [2]. With the completion of the complete genome sequences, new perspectives on rickettsial evolution have been acquired. Apart from the traditional classification based on their morphological, antigenic, and metabolic characteristics, phylogenomic studies showed that the genus Rickettsia was classified into four different groups, including the well-defined SFG and TG, the $R$. belli group and the $R$. canadensis group [2, 22]. Until now, 27 characterized and dozens of as yet uncharacterized strains had been recognized worldwide [2]. The availability of specific and sensitive molecular tools used for taxonomic purposes have allowed for the identification of new species of Rickettsia in places where no rickettsioses had been reported. In the current study, the prevalence and molecular characterization of Rickettsia spp. was determined in H. qinghaiensis ticks, which was the dominant tick species and mainly recorded in northwestern China [23, 24].

In China, several Rickettsia spp. had been identified in ticks from different geographical locations, i.e. $R$. sibirica subsp. sibirica in D. silvarum and D. sinicus in northern China [8]; R. sibirica subsp. mongolitimonae in H. asiaticum in Inner Mongolia [25]; $R$. heilongjiangensis in $D$. silvarum in Heilongjiang and Yunnan [26, 27]; $R$. japonica in H. longicornis in Zhejiang [3]; $R$. slovaca and $R$. raoultii in D. silvarum in Xinjiang [28]; $R$. monacensis in I. persulcatus in central China [29]. Those studies indicate that numerous tick species maintain or transmit Rickettsia. In this study, we first reported the Rickettsia infections in $H$. qinghaiensis ticks, and high prevalences of Rickettsia (18.5\%) and SFG rickettsiae (16.3 \%) infections were observed in study site. The hard ticks $H$. qinghaiensis, a distinctive species common in the Qing-Tibetan Plateau, is a three-host tick and preferentially infests domestic animals, such as sheep, goats, yaks and cattle $[16,23,24]$. Previous studies have 


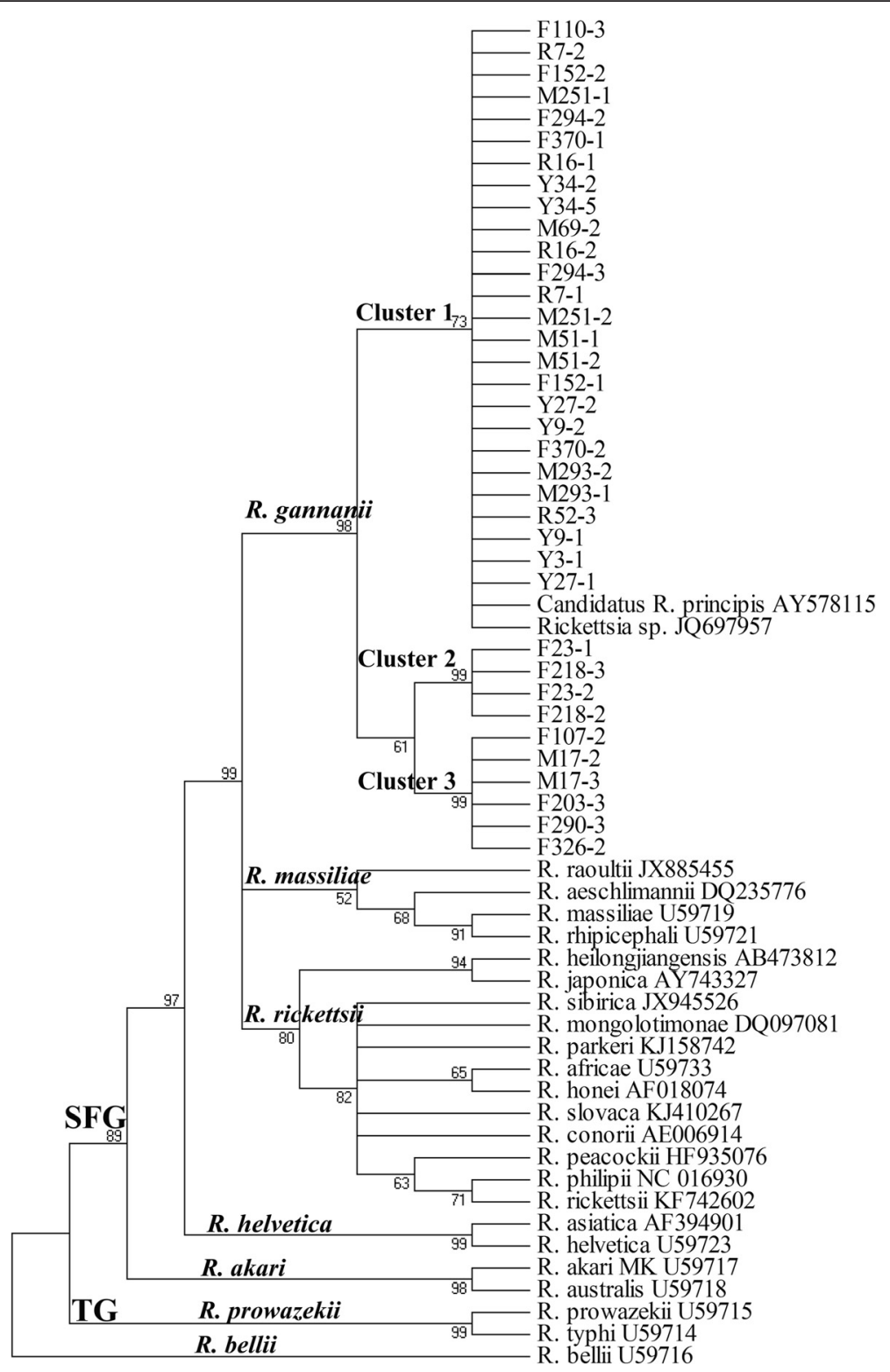

Fig. 1 Phylogenetic tree based on gltA gene sequences of SFG rickettsiae. Bootstraps analysis was performed with 1000 replicates

demonstrated that $H$. qinghaiensis could transmit Theileria sp. and Babesia sp. for small ruminants [23, 24]. Recently, it has also been shown to be naturally infected with Borrelia burgdorferi (s.l.) and Anaplasma phagocytophilum, which are well-known human pathogens in the world [30, 31]. Taken together, our results suggest the potential role of $H$. qinghaiensis ticks as a reservoir host and carrier for piroplasmosis, Lyme disease, anaplasmosis and rickettsioses in this region.

The gltA and ompA genes were considered sufficiently variable to determine more reliable phylogenetic relationships within the genus Rickettsia [17, 20]. Previous report have demonstrated that SFG rickettsiae could be subdivided into four subgroups: $R$. rickettsii, $R$. massiliae, $R$. helvetica and $R$. akari [4]. In this study, phylogenetic tree inferred from glt $A$ and $о m p A$ gene sequences revealed that three clusters of SFG rickettsiae were identified in $H$. qinghaiensis and these three different SFG rickettsiae clustered together in a subgroup separate from other known four SFG rickettsiae subgroups (Figs. 1 and 2). on the data presented here, we believe that the subgroup should be strongly considered as a new SFG rickettsiae subgroup, and we formally propose that these be named "Candidatus Rickettsia gannanii" related strains in recognition of the area where it was detected. In this subgroup, the cluster one may be the most dominant SFG rickettsiae distributed in study site (Figs. 1 and 2). 


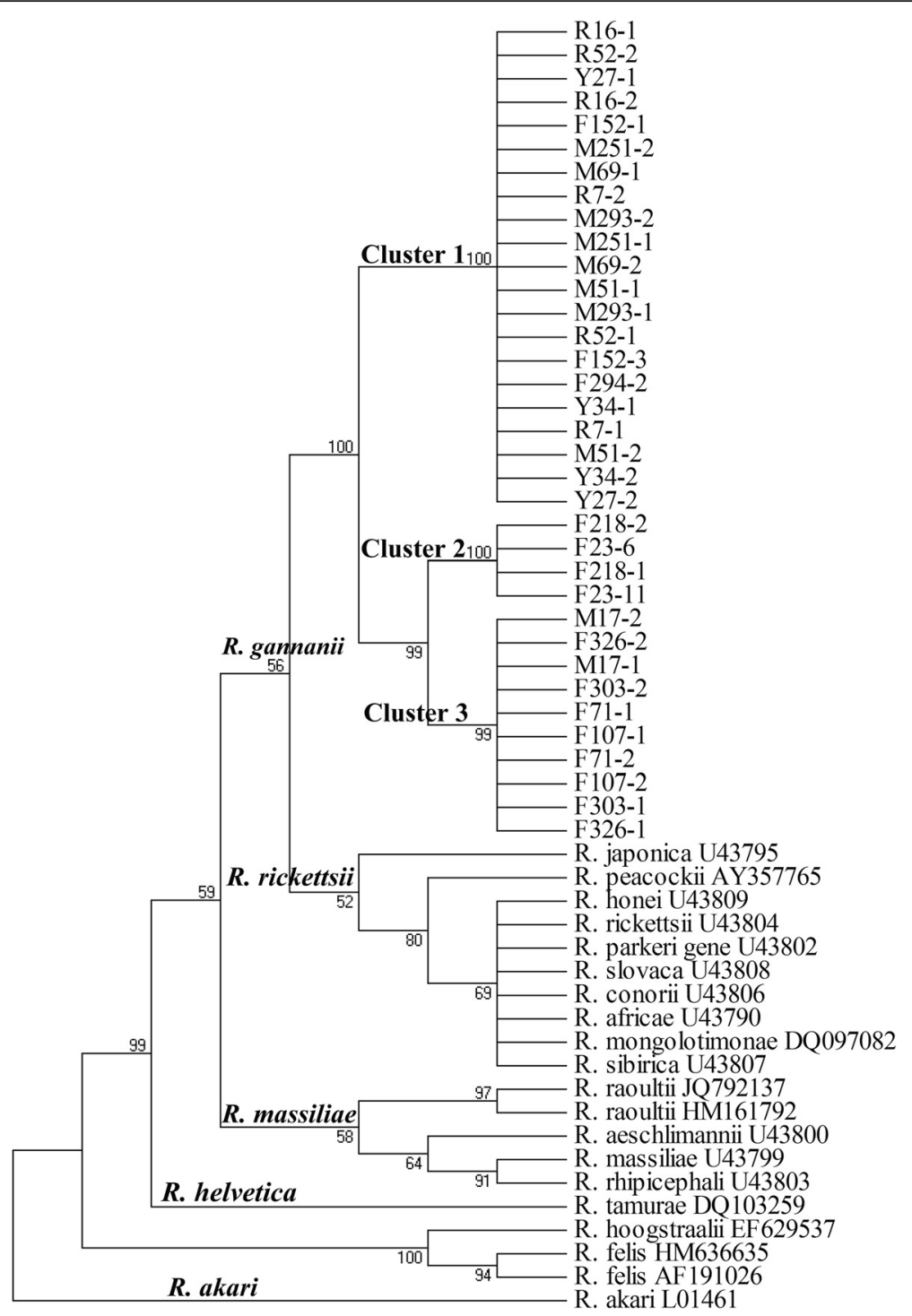

Fig. 2 Phylogenetic tree based on ompA gene sequences of SFG rickettsiae. Bootstraps analysis was performed with 1000 replicates

Some rickettsiae have been reported to be specifically associated with tick species, which are highly dependent on their biotopes [2]. Previous reports showed that $R$. conorii conorii seems to associate mainly with Rhipicephalus sanguineus sensu lato, Haemaphysalis leachi and Rhipicephalus simus in the Mediterranean region and Sub-Saharan Africa [2, 32]. In this study, three different SFG rickettsiae were identified in $H$. qinghaiensis ticks. The geographical distribution and associations between the "Candidatus Rickettsia gannanii" related strains and arthropod species should be further investigated.

In summary, our results showed discrepant SFG rickettsiae were circulating in northwest China. While the SFG rickettsiae identified in the $H$. qinghaiensis ticks have not been linked to human cases in the area, additional studies are therefore needed to determine if these Rickettsia spp. has any public health significance.

\section{Conclusions}

This study represents the first published record of the detection of Rickettsia spp. in H. qinghaiensis ticks. Furthermore, on the basis of the sequence and phylogenetic data, it represents a putative novel SFG rickettsiae subgroup in $H$. qinghaiensis ticks from northwest China.

\section{Competing interests \\ The authors declare that they have no competing interests.}

\section{Authors' contributions}

$H Y, J L$ and $J Y$ designed this study and critically revised the manuscript. ZL, ZT and QN participated in its design, coordination and manuscript revision. $J Y, Y L, Z L$ and $J L$ participated in sample collection. JY, RH, QN, GG and GL 
performed the experiments, data analysis, and drafted the manuscript. All authors read and approved the final manuscript.

\section{Acknowledgements}

This study was financially supported by the NSFC (№31372432, №31201899, №31272556, №31402189, №31471967), ASTIP, FRIP (2014ZL010), CAAS; Creative Research Groups of Gansu Province (№1210RJIA006); NBCIS CARS-38, Special Fund for Agro-scientific Research in the Public Research (№201303035, №201303037), MOA; 973 Program (2015CB150300), Supporting Program (2013BAD12B03, 2013BAD12B05), MOST, China; Jiangsu Co-innovation Center programme for Prevention and Control of Important Animal Infectious Diseases and Zoonoses, State Key Laboratory of Veterinary Etiological Biology Project.

\section{Author details}

${ }^{1}$ State Key Laboratory of Veterinary Etiological Biology, Key Laboratory of Veterinary Parasitology of Gansu Province, Lanzhou Veterinary Research Institute, Chinese Academy of Agricultural Science, Xujiaping 1, Lanzhou, Gansu 730046, P. R. China. ${ }^{2}$ Jiangsu Co-innovation Center for Prevention and Control of Important Animal Infectious Diseases and Zoonoses, Yangzhou 225009, P. R. China.

Received: 18 November 2015 Accepted: 4 March 2016

Published online: 12 March 2016

\section{References}

1. Raoult D, Roux V. Rickettsioses as paradigms of new or emerging infectious diseases. Clin Microbiol Rev. 1997;10(4):694-719.

2. Merhej V, Angelakis E, Socolovschi C, Raoult D. Genotyping, evolution and epidemiological findings of Rickettsia species. Infect Genet Evol. 2014;25: 122-37.

3. Sun J, Lin J, Gong Z, Chang Y, Ye X, Gu S, Pang W, Wang C, Zheng X, Hou J, et al. Detection of spotted fever group Rickettsiae in ticks from Zhejiang Province, China. Exp Appl Acarol. 2015;65(3):403-11.

4. Merhej $V$, Raoult D. Rickettsial evolution in the light of comparative genomics. Biol Rev Camb Philos Soc. 2011;86(2):379-405.

5. Anstead CA, Chilton NB. Detection of a novel Rickettsia (Alphaproteobacteria: Rickettsiales) in rotund ticks (|xodes kingl) from Saskatchewan, Canada. Ticks Tick Borne Dis. 2013:4(3):202-6.

6. Rydkina E, Roux V, Rudakov N, Gafarova M, Tarasevich I, Raoult D. New Rickettsiae in ticks collected in territories of the former soviet union. Emerg Infect Dis. 1999:5(6):811-4.

7. Wang Y, Liu Z, Yang J, Chen Z, Liu J, Li Y, Luo J, Yin H. Rickettsia raoultii-like bacteria in Dermacentor spp. ticks, Tibet, China. Emerg Infect Dis. 2012;18(9): 1532-4.

8. Yu X, Jin Y, Fan M, Xu G, Liu Q, Raoult D. Genotypic and antigenic identification of two new strains of spotted fever group rickettsiae isolated from China. J Clin Microbiol. 1993:31(1):83-8.

9. Parola P, Paddock CD, Socolovschi C, Labruna MB, Mediannikov O, Kernif T, Abdad MY, Stenos J, Bitam I, Fournier PE, et al. Update on tick-borne rickettsioses around the world: a geographic approach. Clin Microbiol Rev. 2013;26(4):657-702.

10. Bechah Y, Capo C, Mege JL, Raoult D. Epidemic typhus. Lancet Infect Dis. 2008;8(7):417-26.

11. Azad AF. Epidemiology of murine typhus. Annu Rev Entomol. 1990;35:553-69.

12. Raoult D, Parola P. Rickettsial diseases. New York: Informa Healthcare; 2007.

13. Socolovschi C, Pages F, Raoult D. Rickettsia felis in Aedes albopictus mosquitoes, Libreville, Gabon. Emerg Infect Dis. 2012;18(10):1687-9.

14. Paddock CD, Sumner JW, Comer JA, Zaki SR, Goldsmith CS, Goddard J, McLellan SL, Tamminga CL, Ohl CA. Rickettsia parkeri: a newly recognized cause of spotted fever rickettsiosis in the United States. Clin Infect Dis. 2004; 38(6):805-11.

15. Dobler G, Wolfel R. Typhus and other rickettsioses: emerging infections in Germany. Dtsch Arztebl Int. 2009;106(20):348-54.

16. Deng GF, Jiang ZL. Economic insect fauna of China, Fasc 39 Acari: Ixodiate. Beijing: Science Press; 1991.

17. Roux V, Rydkina E, Eremeeva M, Raoult D. Citrate synthase gene comparison, a new tool for phylogenetic analysis, and its application for the rickettsiae. Int J Syst Bacteriol. 1997;47(2):252-61.

18. Roux V, Fournier PE, Raoult D. Differentiation of spotted fever group rickettsiae by sequencing and analysis of restriction fragment length polymorphism of PCR-amplified DNA of the gene encoding the protein rOmpA. J Clin Microbiol. 1996:34(9):2058-65.

19. Tamura K, Dudley J, Nei M, Kumar S. MEGA4: Molecular Evolutionary Genetics Analysis (MEGA) software version 4.0. Mol Biol Evol. 2007;24(8): 1596-9.

20. Raoult D, Fournier PE, Eremeeva M, Graves S, Kelly PJ, Oteo JA, Sekeyova Z, Tamura A, Tarasevich I, Zhang L. Naming of Rickettsiae and rickettsial diseases. Ann N Y Acad Sci. 2005;1063:1-12.

21. Mediannikov O, Sidelnikov Y, Ivanov L, Fournier PE, Tarasevich I, Raoult D. Far eastern tick-borne rickettsiosis: identification of two new cases and tick vector. Ann N Y Acad Sci. 2006;1078:80-8.

22. Merhej V, El Karkouri K, Raoult D. Whole genome-based phylogenetic analysis of Rickettsiae. Clin Microbiol Infect. 2009;15 Suppl 2:336-7.

23. Gao J, Luo J, Fan R, Fingerle V, Guan G, Liu Z, Li Y, Zhao H, Ma M, Liu J, et al. Cloning and characterization of a cDNA clone encoding calreticulin from Haemaphysalis qinghaiensis (Acari: Ixodidae). Parasitol Res. 2008; 102(4):737-46.

24. Ma M, Guan G, Chen Z, Liu Z, Liu A, Gou H, Ren Q, Li Y, Niu Q, Yang J, et al. The life cycle of Haemaphysalis qinghaiensis (Acari: Ixodidae) ticks under laboratory conditions. Exp Appl Acarol. 2013;59(4):493-500.

25. Zhang L, Jin J, Fu X, Raoult D, Fournier PE. Genetic differentiation of Chinese isolates of Rickettsia sibirica by partial ompA gene sequencing and multispacer typing. J Clin Microbiol. 2006;44(7):2465-7.

26. Fournier PE, Dumler JS, Greub G, Zhang J, Wu Y, Raoult D. Gene sequencebased criteria for identification of new rickettsia isolates and description of Rickettsia heilongiiangensis sp. nov. J Clin Microbiol. 2003:41(12):5456-65.

27. Liang CW, Zhao JB, Li J, Chang LT, Yu HL, Zhang LX, Zhang L, Yu XJ. Spotted fever group Rickettsia in Yunnan Province, China. Vector Borne Zoonotic Dis. 2012;12(4):281-6.

28. Tian ZC, Liu GY, Shen H, Xie JR, Luo J, Tian MY. First report on the occurrence of Rickettsia slovaca and Rickettsia raoultii in Dermacentor silvarum in China. Parasit Vectors. 2012;5:19.

29. Li W, Liu L, Jiang X, Guo X, Garnier M, Raoult D, Parola P. Molecular identification of spotted fever group Rickettsiae in ticks collected in central China. Clin Microbiol Infect. 2009;15 Suppl 2:279-80.

30. Yang J, Liu Z, Guan G, Che R, Niu Q, Li Y, Liu J, Ma M, Ren Q, Liu A, et al. Evaluation of molecular methods for detection of Borrelia burgdorferi senso lato in ticks. Diagn Microbiol Infect Dis. 2012;73(1):80-3.

31. Yang J, Liu Z, Guan G, Liu Q, Li Y, Chen Z, Ma M, Liu A, Ren Q, Luo J, et al. Prevalence of Anaplasma phagocytophilum in ruminants, rodents and ticks in Gansu, north-western China. J Med Microbiol. 2013;62(Pt 2):254-8.

32. Drancourt M, Kelly PJ, Regnery R, Raoult D. Identification of spotted fever group rickettsiae using polymerase chain reaction and restrictionendonuclease length polymorphism analysis. Acta Virol. 1992:36(1):1-6.

\section{Submit your next manuscript to BioMed Central and we will help you at every step:}

- We accept pre-submission inquiries

- Our selector tool helps you to find the most relevant journal

- We provide round the clock customer support

- Convenient online submission

- Thorough peer review

- Inclusion in PubMed and all major indexing services

- Maximum visibility for your research

Submit your manuscript at www.biomedcentral.com/submit
) Biomed Central 